\title{
Matemática e Metafísica em Platão e Aristóteles
}

\section{Mathematics and Metaphysics in Plato and Aristotle}

\author{
Alberto Leopoldo Batista Neto \\ https://orcid.org/0000-0002-3070-7934 - Email: albertolbneto@yahoo.com.br
}

\section{RESUMO}

As diferenças entre os modos de conceber a realidade matemática estão no próprio centro da divergência entre as filosofias de Platão e de Aristóteles, figurando de maneira crucial no estágio das controvérsias metafísicas que separam os dois filósofos. Platão, argumenta-se, mantém-se fiel à tradição filosófica anterior, ao estabelecer uma hierarquia ontológica que espelha diretamente os graus de inteligibilidade dos objetos da ciência. Aristóteles subverte fundamentalmente essa tendência, ao subordinar a matemática à física e propor, no lugar da matemática, a lógica como modelo primário da razão dianoética.

Palavras-chave: Matemática. Metafísica. Platão. Aristóteles. Revolução científica.

\begin{abstract}
The diferences between their respective ways of conceiving mathematical reality are at the very heart of the divergence between the philosophies of Plato and Aristotle, figuring as they do in a crucial way in the stage of the metaphysical controversies that divide the two philosophers. Plato, it is argued, keeps faithful to the earlier philosophical tradition in establishing an ontological hierarchy that directly mirrors the degrees of intelligibility of the objects of Science. Aristotle subverts fundamentally such a tendency in subordinating mathematics to physics and proposing, in the place of mathematics, logic as the primary model of dianoetic reason.
\end{abstract}

Keywords: Mathematics. Metaphysics. Plato. Aristotle. Scientific revolution. 


\section{Introdução}

A disputa acerca do estatuto ontológico dos objetos do discurso matemático encontra-se entre as questões de maior relevo na tradição filosófica do Ocidente. Com efeito, trata-se, talvez, do centro em torno do qual processa o curso principal das revoluções intelectuais da civilização europeia.

Para além de Tales, reputado como fundador tanto da Filosofia como da Matemática (como ciência demonstrativa'), avulta o nome de Pitágoras, que figura como fundador (ainda que mítico), da tendência intelectual que busca expressamente na matemática o princípio das leis que constituem e ordenam o universo. Sua atração sobre o pensamento de Platão (ao menos sobre o seu pensamento tardio ${ }^{2}$ ) é tão notória que, em períodos subsequentes, chega a ser difícil distinguir entre platonismo e pitagorismo ${ }^{3}$. Pitágoras teria sido, segundo o filósofo e matemático Alfred North Whitehead (2006, p. 44), o primeiro a apreender, em condições de suficiente generalidade, o princípio que possibilita a captação da "harmonia razoável do ser", intuindo a importância do número como indispensável recurso à representação de quanto subjaz à ordem da natureza. Também considera o mundo ideal platônico como versão requintada e revista da mesma tese pitagórica (2006, p. 45). A matemática é, para Platão, não apenas a ciência - capaz de ordenação conceitual-discursiva - dotada de maior rigor e veracidade, mas ainda o modelo segundo o qual é modelado todo o reino do ser, e em razão do qual ele se torna inteligível, na exata medida em que é inteligível.

O ideal platônico-pitagórico, tendo embora permanecido um motivo poderoso ao longo de toda a história intelectual do Ocidente, eventualmente triunfando no ideal moderno de ciência, não prevaleceu de modo contínuo, nem deixou de ser alvo de ataques vigorosos. $O$ mais capaz entre os discípulos de Platão, Aristóteles, parece levantar sérios problemas sobre o estatuto da matemática como condição primária da ordem e da inteligibilidade do real.

\section{Duas filosofias da matemática, duas metafísicas}

Para entender as posições em conflito, é preciso conhecer algumas de suas pressuposições. Em primeiro lugar, cumpre recordar que o pensamento de um filósofo não pode ser representado como um objeto rígido, imutável e insensível ao tempo (como podem ser alguns objetos de sua ontologia). Obviamente, há mais do que um "pensamento platônico" e há mais do que um "pensamento aristotélico". Quais dentre estes objetos estão efetivamente em confronto? Aristóteles faz diversas críticas a Platão, muitas das quais podem ser compreendidas

\footnotetext{
${ }^{1}$ Evidentemente, não afirmamos que Tales tenha, realmente, efetuado algo como uma demonstração, ou até que algo como uma técnica demonstrativa estivesse disponível para os gregos de sua geração ou mesmo das próximas. Burnet (2006, p. 62) chega a afirmar que sua fama como geômetra provavelmente deve-se tão-somente à aplicação de certas regras já conhecidas pelos egípcios para resolver problemas práticos que aqueles não solucionaram. Entre os primeiros pitagóricos, contudo, parece haver, senão o desenvolvimento de técnicas propriamente demonstrativas, ao menos a tentativa sistemática de fazer ver a validade geral de certos resultados, dissociada de interesses práticos (BURNET, Op. cit., p. 112; KNEALE; KNEALE, 1971, p. 3-5).

2 Kahn (2007, p. 37ss), que considera problemática a disjunção das doutrinas supostamente "órficas" e aquelas propriamente "pitagóricas" (p. 37ss), julga haver razão para supor uma influência mais remota do pitagorismo sobre Platão, detectável em obras como Górgias e Fédon (p. 73ss) (BURNET, loc. cit).

${ }^{3}$ Mesmo pensadores neopitagóricos hostis a Platão e seus discípulos imediatos, como Moderado de Gades (séc. I d.C.), buscando dissociar-se daqueles, não deixaram, para detratá-los, de recorrer à acusação de plágio (KAHN, Op. cit., p. 137). Em todo caso, Diógenes Laércio chega a reportar que Platão comprou (ou pediu para comprar, em outro relato) um ou vários tratados pitagóricos, que teria plagiado no Timeu (MATTÉl, 2007, p. 65). A semelhança de muitas ideias presentes nos diálogos platônicos com ideias atribuídas pelos doxógrafos a membros mais antigos da ordem pitagórica é patente (MATTÉl, p. 47ss).
} 
como críticas a determinada fase de seu desenvolvimento filosófico, talvez superada pelo próprio Platão em período posterior ${ }^{4}$. Todavia, no assunto em pauta, o alvo comum das críticas do pensador de Estagira deve ser mesmo o Platão tardio, o Platão dos "números ideais" e dos entes matemáticos "intermediários", o mesmo que ministrou o célebre curso "Sobre o Bem", ao qual, segundo testemunho de Aristóxeno (Harm. Elem., II 39-40 DA RIOS, apud REALE, 2004, p. 162), muitos acorreram, julgando tratar dos itens visados pelos modos ordinários da aspiração humana, saindo, porém, em grande parte, frustrados e perplexos, ao perceber que se falava quase exclusivamente de coisas matemáticas ${ }^{5}$.

Um auxílio importante para compreender a posição da matemática na filosofia de Platão é a comparação da linha dividida, tal como exposta no livro VI da República ${ }^{6}$. Trata-se de um segmento, verticalmente orientado, dividido em duas partes desiguais, respectivamente divididas, na sequência, em duas partes (cada uma), também desiguais, mas de tal modo que a razão entre as partes do segmento maior (da primeira divisão) determinam proporção idêntica à existente entre as partes do segmento menor, e idêntica à razão entre os dois segmentos iniciais. Embora não esteja explícito no texto platônico, é ponto pacífico que os dois fragmentos intermediários da linha sejam congruentes (cf. Ibid., passim; SHAPIRO, 2000, p. 53 [n.]). Na parte superior da linha (resultante da primeira divisão), encontramo-nos no campo do conhecimento (episteme) propriamente considerado, enquanto na seção inferior, achamo-nos no campo da opinião (doxa). O âmbito da episteme, por sua vez, divide-se em "entendimento" (diánoia) e "inteligência" (ou "intuição" - nóesis); enquanto o da doxa divide-se em conjectura (eikasía) e crença (pístis). A esta divisão corresponde a divisão da realidade em planos ontológicos ${ }^{7}$. A episteme atinge o inteligível, subdividido nos domínios das ideias e das formas matemáticas (intermediárias $^{8}$ ), enquanto a doxa alcança o sensível, subdividido, por sua vez, em objetos físicos e suas "sombras" (fantasmas, ou aspectos sensíveis). Tais divisões revelam igualmente uma gradação entre os aspectos da realidade (e seus modos de apreensão) segundo sua maior vinculação à satisfação dos interesses práticos do homem (sentido descendente) ou à pura contemplação (theoría - sentido ascendente) ${ }^{9}$, além de uma ordem unilinear de dependência (tanto em realidade quanto em inteligibilidade) dos planos inferiores em relação aos superiores.

Entendidos como objetos intermediários entre a ordem das ideias (eidética) e a das realidades sensíveis, os entes matemáticos são seres inteligíveis, mas dotados de multiplicidade (ARISTÓTELES, Metaphysica, I, 6, 987b 14-18, também REALE, Op. cit., p. 173-174; CATTANEI,

\footnotetext{
${ }^{4}$ Segundo Erickson e Fossa (op. cit., passim), as principais críticas Aristotélicas a Platão como "amigo das Formas" não se aplicariam ao Platão maduro, com o qual Aristóteles seria, de algum modo, reconciliável (ao gosto neoplatônico). Os mesmos autores não deixam, contudo, de observar que a substituição, operada por Aristóteles, da matemática pela lógica como ciência "dianoética" par excellence, em relação ao Platão maduro, acaba por constituir um polo tensional de primeira importância na história da metafísica.

${ }^{5} \mathrm{~A}$ atenção dada à repercussão dos conteúdos do referido curso, assim como o papel em geral atribuído às chamadas "doutrinas não-escritas", referidas explicitamente por Aristóteles em Physica IV, 209b 11-17 e presumivelmente comentada em muitos outros trechos, em que falta correspondência estrita com o conteúdo dos diálogos, suscitou, nas últimas décadas, importantes discussões acerca da mudança do paradigma hermenêutico dos textos platônicos, balizada pela consideração dessas doutrinas (centrais) como chaves interpretativas. Para discussões prolongadas sobre o assunto, (REALE, Op.cit.; SZLEZÁK, 2005). De particular importância para a discussão da matemática platônica, (HÖSLE, 2008, p. 64-81; CATTANEI, 2005., p 255ss). Reale (2005, p. 173) chega a dizer, seguindo Krämer e Gadamer, que algumas dentre essas doutrinas (como a dos "números ideais") pode ser consideravelmente mais precoce do que usualmente se imagina.

${ }^{6} 509$ D - 511 A. Para uma discussão detalhada e original, (ERICKSON; FOSSA, Op. cit., também, MATTÉl, 2010, p. 61ss).

7 Segundo o axioma parmenideano: "o mesmo é o conhecer e o ser" (Fr. 3 Diels-Kranz, apud REALE (Op. cit., p. 174)).

${ }^{8}$ Há um certo debate na literatura sobre a propriedade da classificação das entidades matemáticas como habitantes de uma espécie de intermundum entre as formas puras (ideias) e a realidade sensível, uma vez que a terminologia, baseada no uso aristotélico (cf. Metaphysica B 2997 b 2-3 - onde aparece a expressão "metaxy"), remete a "doutrinas não-escritas". Para discussão, cf. CATTANEI, Op. cit., p. 255ss.

${ }^{9}$ Esta ordem é claramente sugerida na alegoria da caverna (Republica, VII). (Cf. ERICKSON; FOSSA, ibid., passim).
} 
2005, p. 255ss), em ordem a possibilitar as operações sobre eles efetuadas pelos matemáticos, que os podem instanciar sob condições diversas (há "múltiplos triângulos" congruentes, e múltiplas determinações para a mesma essência triangular - e. g. isósceles, escaleno e equilátero). Além do mais, a ciência obtenível sobre eles não se funda em princípios puramente matemáticos, mas se ergue sobre hipóteses (do ponto de vista matemático) que somente serão estabelecidas em suas bases se nos remetermos às ideias puras ${ }^{10}$.

Interessantemente, conforme mencionamos, os segmentos da linha dividida correspondentes à matemática e à física são congruentes. Isso descortina uma realidade de "espelhamento". As formas físicas, portanto, refletem as características dos entes matemáticos, porém como num "espelho escuro", de vez que se situam na seção inferior da linha. Tal parece proceder, de acordo com o modelo cosmológico do Timeu, da resistência imposta pela necessidade (khora), receptáculo das formas moldadas pelo demiurgo (Timaeus, 48) ${ }^{11}$. A tridimensionalidade do espaço sugere que as formas cosmológicas devem ser compostas pelos sólidos da estereometria, que fornece, portanto, as bases do primeiro modelo geométrico para a química, que haveria de deixar fascinado e perplexo um dos pais-fundadores da teoria atômica contemporânea (HEISENBERG, 1996, p. 15ss). ${ }^{12}$

Erickson e Fossa (2006, passim) defendem que a linha dividida é construída segundo um algoritmo para a produção de segmentos cujas medidas produzem razões irredutíveis ${ }^{13}$ tais que aquelas dos extremos são quadrados perfeitos e a de cada um dos segmentos intermediários (que se "espelham") corresponde à média geométrica entre elas (que, sendo inteiras as raízes das medidas dos extremos, será esta também um valor integral - conforme o chamado "teorema de Platão", cf. ERICKSON; FOSSA, Op. cit., p. 45). O mesmo algoritmo produziria diferentes linhas divididas, que haveriam de tornar possíveis, por sua vez, articulações localizadas, revelando a estrutura comum do tratamento platônico dos diversos temas que lhe ocupam o pensamento. Esta consideração reveste particular significado por revelar a importância da matemática na própria estruturação da filosofia platônica, o que revela fundamental consonância com a opinião de Gaiser (apud CATTANEI, Op. cit., p. 285) segundo a qual, em Platão, justamente porque situada entre o plano superior das ideias, e o plano inferior das formas cósmicas, constitui o modelo da própria realidade, informando o que lhe está abaixo e abrindo-se à dimensão superior que a fundamenta (REALE, Op. cit., p. 176).

Com efeito, parece que Platão elabora suas explicações acerca dos diversos níveis da realidade, não através de um sistema de encadeamentos de causas eficientes (quer teleologicamente direcionadas, quer não ${ }^{14}$ ) e efeitos sucessivos, mas segundo um requintado sistema de analogias - elas próprias fundadas na grande realização matemática do período: a teoria eudo-

\footnotetext{
${ }^{10}$ Segundo Hösle (Op. cit. p.213ss), há indícios de ter havido uma grave "crise fundacional" na Matemática dos dias da Academia, em torno à questão da "euclidianidade" da geometria (i.e., a validade do postulado das paralelas), cuja saída pode ter sido apontada por Platão justamente em termos não propriamente matemáticos, mas expressamente metafísicos (a geometria "euclidiana" legitima a unicidade da medida da soma dos ângulos internos de um triângulo - igual a dois retos - e, sendo "mais unitária", haveria de ser "mais verdadeira"; observe que dita solução tampouco faz referência a qualquer espécie de "intuição sensível", à maneira de Kant).

${ }^{11} \mathrm{~A}$ necessidade parece ligar-se à espacialidade, e esta à irracionalidade, tal como descoberta no domínio da própria matemática, pela descoberta da incomensurabilidade (e, portanto, irredutibilidade à proporção, entendida no sentido originário de razão entre números inteiros) na geometria (como no caso da diagonal do quadrado). Por isso (como também por sua menor generalidade), a geometria encontra-se, entre as ciências matemáticas, mais próxima ao limiar inferior da linha, embora tratando ainda de intermediários inteligíveis. Isso sugere a existência de uma linha dividida no seio da própria diánoia (ERICKSON; FOSSA, Op. cit. p. 106ss).

12 Para detalhes sobre a estruturação matemática da química platônica, (ERICKSON; FOSSA, 2005, p. 11-27; 69-89).

${ }^{13}$ I.e., medidas por números inteiros "primos entre si".

${ }^{14}$ Este parece ser o fulcro da divergência entre a cosmovisão "aristotelizante" do final da Idade Média e o paradigma científico moderno que - curiosa mas decerto não acidentalmente -, traz de volta a matemática ao coração da episteme europeia.
} 
xiana das proporções ${ }^{15}$. A "modelagem" dos estratos inferiores da realidade em conformidade com a configuração dos estratos superiores não somente submete e condiciona o ser e a inteligibilidade do mundo sensível à existência "separada" e anterior dos objetos matemáticos e de seus modos de relacionamento ${ }^{16}$, mas obedece a um padrão de proporcionalidade "matematicamente" concebido. No interior de cada segmento de uma linha dividida, podemos encontrar ainda o mesmo padrão de proporcionalidade que relaciona as partes da linha original. Aparentemente, isso é verdadeiro no próprio reino das ideias ${ }^{17}$. O que a doutrina ${ }^{18}$ dos números ideais parece sugerir é que, na dimensão eidética, as formas puras dos números (não-matemáticos, e, portanto, insensíveis às operações matemáticas que multiplicam as instanciações dos objetos inteligíveis intermediários) condicionam a estruturação das ideias individuais ${ }^{19}$. Ou seja: as "essências" ou ideias dos números, mesmo não sendo elas próprias números, têm precedência sobre as demais ideias (incluindo, nessa ordem, as figuras ideais - ou ideias dos entes geométricos - e as formas das entidades físicas), deixando-se condicionar apenas pelos princípios, assim como os entes intermediários se deixam condicionar pelas ideias (nova analogia).

Assim são os entes matemáticos para Platão: habitantes de um segmento da realidade dotado de maior consistência ontológica que o das realidades físicas, anterior a estas, condição de sua existência e inteligibilidade. O que implica: existência separada - ou, em terminologia aristotélica: realidade substancial.

Como Platão, Aristóteles em nenhum momento põe em dúvida a verdade e a objetividade das ciências matemáticas que maturavam em sua época. Com isso queremos dizer que se trata, para ele, não somente de um discurso verdadeiro e certo, mas também que versa sobre um domínio real de objetos e que, portanto, os entes de que falam os matemáticos - como números, segmentos e proporções - realmente existem ${ }^{20}$. O cerne da controvérsia entre os dois filósofos se há de encontrar precisamente na questão sobre o modo de ser das referidas entidades.

Para Aristóteles, o matemático (e. g. o geômetra) debruça-se não sobre qualquer coisa de realmente separada do mundo físico, mas volta seu olhar, de algum modo, para esse mesmo mundo físico, concentrando-se, porém, em um certo aspecto seu (Physica II, 2, 193b 23 - 194a 12). O geômetra concebe o ente físico enquanto concretização de certa figura geométrica. $\mathrm{O}$ aritmético, por sua vez, concentra-se nos objetos físicos enquanto pensados como unidades indivisíveis ${ }^{21}$. Uma vez assim caracterizados, seria possível operar sobre esses objetos abstratos ${ }^{22}$ (a começar, por exemplo, pela conjugação de unidades para formar o nú-

\footnotetext{
15 Ou seja: analogias. (ERICKSON; FOSSA, 2006, passim; CATTANEI, Op. cit., passim).

${ }^{16}$ Evidentemente, não constituindo este domínio o ponto mais alto da hierarquia platônica, deve subordinar-se, por sua vez, ao domínio das ideias.

${ }^{17}$ Erickson e Fossa (p. 61) aplicam o paradigma da linha dividida às ideias supremas de Um, Identidade e Diferença e Ser. Os termos médios, no entanto, são não raro fundidos no princípio da "Díade Indefinida" nos testemunhos das "doutrinas não-escritas". Mas de vez que este mesmo princípio é por vezes apresentado na forma de um par de opostos ("grande e pequeno"), e, juntamente com o Um, determina o ser, talvez não haja choque entre as duas leituras. Em todo caso, a protologia (doutrina dos primeiros princípios) de Platão - discutida em diálogos como o Parmênides, o Sofista e o Filebo - parece ser de difícil determinação (talvez por pertencer a uma zona da realidade somente tradutível discursivamente em termos, eles próprios, analógicos).

18 "Não-escrita", mas reportada por Aristóteles, Alexandre, Simplício e Sexto Empírico (REALE, ibid., p 167ss).

19 Reale (p. 169ss), seguindo Gaiser, considera que os números ideais que compõem a Década primitiva, podem ser entendidos como logoi ou relações numéricas de caráter generalíssimo, encontrando-se na origem do processo diairético ("método da divisão") que compõe logicamente as ideias particulares.

${ }^{20}$ Seguindo terminologia adotada por Shapiro (p. 25ss), atribuímos a Aristóteles tanto a posição de realista em valor de verdade (realist in truth-value) quanto de realista em ontologia (realist in ontology).

${ }^{21}$ A aritmética grega (opondo-se nisso aos cálculos vulgares do homem da rua) repudiava o número fracionário (exceto se concebido como razão - i.e., uma relação entre números, e não número em sentido próprio), assim como o número negativo (CATTANEI, p. 220-222)

${ }^{22}$ I.e., resultantes de "abstração" ou "subtração" (afaíresis) dos objetos sensíveis a que imanem
} 
mero - numa nova unidade, portanto) como se constituíssem um domínio autônomo da realidade (CATTANEI, p. 47ss).

Muitas interpretações são propostas para elucidar o estatuto ontológico próprio desses objetos, no pensamento aristotélico ${ }^{23}$. O que aqui nos interessa, contudo, é a radical subversão, por parte de Aristóteles, da hierarquia ontológica e do método filosófico erigidos por seu antigo mestre. Aristóteles opera um verdadeiro deslocamento de eixo da realidade: 0 mundo sensível passa a ser o seu centro ${ }^{24}$. Evidentemente, isso não acarreta, para Aristóteles, a conclusão de que à ciência do mundo sensível corresponda um nível de conhecimento mais exato do que aquele atribuível à matemática. Porém, isto constitui por si mais uma ruptura: uma violação do princípio parmenideano da identidade entre ser e conhecer. $O$ estrato mais profundo e consistente da realidade é a substância (cf. Metaphysica IV; a respeito da questão aqui tratada, BARNES, 2005, p. 69ss). Embora a ontologia aristotélica admita substâncias suprassensíveis que constituem níveis de realidade superiores e mais fundamentais em relação à substância sensível - caracterizada como sínolo: unidade logicamente decomponível em matéria e forma - não é a este domínio suprassensível (e divino - cf. Metaphysica, XII) que concernem os objetos matemáticos. Isso quer dizer, porém, que Aristóteles precisa recusar à matemática o seu papel de "ciência dianoética". Propõe, então, como sua substituta, a lógica (ERICKSON; FOSSA, 2006, p. 165ss).

\section{Considerações finais}

Para Erickson e Fossa (loc. cit.), perpassa toda a história da metafísica ocidental - compreendendo as tentativas de ordenar a realidade segundo sistemas de conceitos - uma forte tensão que opõe, alternadamente, as tentativas de situar a matemática, a lógica ou algum sistema classificatório mais geral que esta (como o de tropos) como modelo primário do conhecimento mediato, i.e., passível de articulação discursiva. Neste quesito, o posicionamento de Aristóteles foi tremendamente influente, sendo de algum modo ainda dominante nos umbrais da revolução científica do século XVII, quando a filosofia torna a procurar o seu modelo ideal no mundo matemático. A dinâmica histórica que atravessa o embate de sistemas ora configurado eventualmente desembocaria no fenômeno conhecido como o fim da filosofia.

Um exame desapaixonado do papel atribuído à matemática nos grandes sistemas metafísicos pode revelar a enorme importância que tais considerações são capazes de acarretar ao pensamento humano. Longe de ser um mero jogo enfadonho com símbolos reservado a especialistas, a matemática pode ser o próprio coração palpitante que bombeia vitalidade para o frágil organismo da Filosofia.

\footnotetext{
${ }^{23}$ Encontramos, por exemplo, uma interpretação ficcionalista em Lear (1982), em cujo caso teríamos que reclassificar Aristóteles como realista em valor de verdade, mas não em ontologia. Brambaugh (1955) propõe uma interpretação da filosofia da matemática de Aristóteles como uma espécie de intuicionismo avant-la-lèttre. Cattanei (p. 179ss) propõe uma interpretação realista (em termos de ontologia).

${ }^{24} \mathrm{Em}$ um certo sentido: os entes sensíveis são primários, quer ontologicamente, em relação a seus predicados (incluindo essência ou natureza específica - cf. Categoriae 2a 11 - 4b 20) quer epistemologicamente, no sentido da acessibilidade a nós (cf. Physica 184a 17-21). Porém, absolutamente, a substância suprassensível é anterior tanto no ser como na ordem do conhecimento (REALE, p. 178ss).
} 


\section{Referências}

ARISTÓTELES. The basic works of Aristotle. Ed. by Richard McKeon. New York: Modern Library, 2001.

BARNES, J. Aristóteles. Trad. Adail Ubirajara Sobral e Maria Stela Gonçalves. 2. ed. São Paulo: Loyola, 2005.

BRAMBAUGH, R. Aristotle as Mathematician. The Review of Metaphysics. v. 8, n. 3, mar. 1955. p. 379-393.

BURNET, J. A aurora da filosofia grega. Trad. Vera Ribeiro. Rio de Janeiro: Contraponto, 2006.

CATTANEI, E. Entes matemáticos e metafísica: Platão, a Academia e Aristóteles em confronto. Trad. Fernando S. Moreira. Prefácios de Imre Toth e Thomas A. Szlezák. São Paulo: Loyola, 2005.

ERICKSON, G. W.; FOSSA, J. A. A linha dividida: uma abordagem matemática à filosofia platônica. Rio de Janeiro: Relume-Dumará, 2006.

ERICKSON, G. W.; FOSSA, J. Número e razão: os fundamentos matemáticos da metafísica platônica. Natal: EDUFRN, 2005.

HEISENBERG, W. A parte e o todo: encontros e conversas sobre física, filosofia, religião e política. Trad. Vera Ribeiro. Rio de Janeiro: Contraponto, 1996.

HÖSLE, V. Interpretar Platão. Trad. Antonio Celiomar Pinto de Lima. São Paulo: Loyola, 2008.

KAHN, C. H. Pitágoras e os pitagóricos: uma breve história. Trad. Luis Carlos Borges. São Paulo: Loyola, 2007.

KNEALE, W.; KNEALE, M. The Development of Logic. London: Oxford (Clarendon), 1971.

LEAR, J. Aristotle's Philosophy of Mathematics. Philosophical Review, 91, 1982. p. 161-192.

MATTÉl, J.-F. Platão. Trad. Maria Leonor Loureiro. São Paulo: UNESP, 2010.

MATTÉl, J.-F. Pitágoras e os pitagóricos. Trad. Constança Marcondes Cesar. 2. ed. São Paulo: Paulus, 2007.

PLATÃO. The Dialogues plus The Seventh Letter. Trad. Benjamin Jowett e J. Harward. Chicago: William Benton, 1952. (Great Books of the Western World).

REALE, G. Para uma nova interpretação de Platão: Releitura da metafísica dos grandes diálogos à luz das “Doutrinas não-escritas”. Trad. Marcelo Perine. 2. ed. São Paulo: Loyola, 2004.

SZLEZÁK, T. A. Ler Platão. Trad. Milton Camargo Mota. São Paulo: Loyola, 2005.

SHAPIRO, S. Thinking about mathematics: The philosophy of mathematics. New York: Oxford, 2000.

WHITEHEAD, A. N. A ciência e o mundo moderno. Trad. Hermann Herbert Watzlawick. São Paulo: Paulus, 2006. 


\section{Sobre o autor}

\section{Alberto Leopoldo Batista Neto}

Doutor em Filosofia. Universidade do Estado do Rio Grande do Norte. Áreas de atuação: Lógica, Filosofia da Ciência, Epistemologia, Metafísica.

Recebido em: 04/04/2020.

Aprovado em: 18/08/2020.
Received: 04/04/2020.

Approved: 18/08/2020. 